\title{
Corantes naturais de aplicação têxtil: avaliação preliminar da toxicidade de urucum Bixa orellana L. (Malvales: Bixaceae) e hibisco Hibiscus sabdariffa L. (Malvales: Malvaceae)
}

\section{Doralice de Souza Luro Balan}

Centro de Estadual de Educação Tecnológica "Paula Souza”. Faculdade de Tecnologia de Americana. Americana. Coordenadoria Têxtil e Moda. Rua Emílio de Menezes, s/n. Vila Amorim. Americana-SP. Brasil (CEP 13469-111). E-mail: dbalan@fatec.edu.br.

Resumo. As empresas têxteis tem preocupações de caráter ambiental, especialmente em relação a seus processos industriais de produção, confecção e moda. Há um interesse do setor na investigação dos corantes naturais para uso em escala comercial, porém faltam estudos qualiquantitativos sobre o impacto ambiental destes produtos. Este artigo tem como objetivo avaliar a toxicidade dos corantes naturais das sementes do urucum Bixa orellana L. (Malvales: Bixaceae) e das flores do hibisco Hibiscus sabdariffa L. (Malvales: Bixaceae). A metodologia utiliza normas de toxicidade em solo com plantas superiores. Para as análises germinativas e de crescimento vegetal são seguidas as normas da ABNT ISO 11269-2:2014. O vegetal selecionado para teste foi o milho Zea mays L. (Poales: Poaceae). Os resultados apontam positivamente para a utilização destes corantes naturais, sendo que ocorreu $50 \%$ de germinação das sementes de milho no $6^{\circ}$ e $7^{\circ}$ dias de testes, respectivamente, para o urucum e para o hibisco. Em todos os experimentos (12 dias), a taxa germinativa foi de $100 \%$. O crescimento radicular e aéreo (28 dias), na presença dos corantes, acompanha os valores do controle. Nas condições experimentais empregadas, efeitos agroquímicos tóxicos graves e limitantes não foram observados na presença dos corantes do urucum e do hibisco. Os estudos devem continuar, contemplando as normas ISO e ABNT para testes de toxicidade, podendo conduzir a ações de inovação e sustentabilidade, esperadas pelo empresário e pelo consumidor do século XXI.

Palavras-chave: Corantes naturais; Toxicidade em plantas superiores; Têxteis sustentáveis.

Abstract. Natural dyes of textile application: preliminary evaluation of the toxicity of achiote Bixa orellana L. (Malvales: Bixaceae) and hibiscus Hibiscus sabdariffa L. (Malvales: Malvaceae). Textile companies have environmental concerns, especially in relation to their industrial processes of production, clothing and fashion. There is an industry interest in the investigation of natural dyes for use on a commercial scale, but there is a lack of qualitative and quantitative studies on the environmental impact of these products. This article aims to evaluate the toxicity of the natural dyes from the seeds of the Bixa orellana L. seeds (Malvales: Bixaceae) and the Hibiscus sabdariffa L. (Malvales: Malvaceae) flowers. The methodology uses standards of toxicity in soil with
Recebido:

$15 / 11 / 2016$

Aceito:

$24 / 06 / 2017$

Publicado:

30/06/2017

Acesso Aberto

Artigo completo

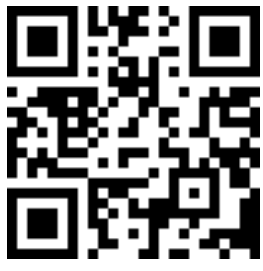

ORCID

(ㄱ) $0000-0002-6210-5452$

Doralice de Souza Luro Balan 
superior plants. For germination and plant growth analyzes, the ABNT ISO 11269-2:2014 are followed. The plant selected for testing was maize Zea mays L. (Poales: Poaceae). The results point positively to the use of these natural dyes, with $50 \%$ germination of corn seeds on the 6th and 7th days of testing, respectively, for achiote and hibiscus. In all experiments (12 days), the germination rate was $100 \%$. The root and aerial growth (28 days) in the presence of the dyes, accompanies the control values. In the experimental conditions employed, severe toxic and limiting agrochemical effects were not observed in the presence of annatto and hibiscus dyes. The studies must continue, contemplating the ISO and ABNT standards for toxicity tests, which may lead to the actions of innovation and sustainability, expected by the entrepreneur and the consumer of the 21st century.

Keywords: Natural dyes; Toxicity in upper plants; Sustainable textiles.

\section{Introdução}

O atual panorama global revela que os recursos naturais estão mais escassos, a concorrência de mercados acirrada e os consumidores estão preocupados em adquirir os produtos chamados ecologicamente corretos.

Assim, surge a necessidade de empreender novas pesquisas e desenvolvimento (P\&D) em variadas áreas do conhecimento.

As empresas têxteis tem preocupações de caráter ambiental, especialmente em relação a seus processos industriais de produção, confecção e moda, buscando por reestruturações organizacionais e operacionais, contemplando uma gestão ambiental adequada para o setor.

Procuram atender às exigências de um novo padrão de produção sustentável e responder aos clientes que passam a exigir das empresas melhoria contínua, com ênfase na capacidade de oferecer produtos e serviços que respeitem a natureza.

Nos últimos anos, a questão ambiental evoluiu tornando-se uma importante preocupação empresarial, num entendimento de que o meio ambiente é seu valioso fornecedor de insumos (Berlin, 2014).

O conceito de sustentabilidade é um assunto extenso e aplicado a contextos de referência, do qual o conceito de Ecologia é o majoritariamente incorporado. A questão ambientalista emerge como consequência da Era Pós-Moderna, e tornou-se um debate delicado do século XXI. Correlaciona-se a uma dinâmica socioeconômico-produtiva, onde a discussão ambiental é provocada por um mundo que enfrenta o aquecimento global, a superpopulação, o esgotamento dos habitats, a escassez de matérias-primas, a toxicidade dos produtos industriais, a poluição do ar, da água e a geração de resíduos sólidos. Mas a "sustentabilidade", não é sinônimo de "Ecologia". Ela inclui o respeito à saúde de trabalhadores, dos consumidores e o debate público contínuo (Tartaglione et al., 2012).

A indústria têxtil tem papel de destaque na economia mundial. Sua multidisciplinaridade engloba um vasto campo de estudos para fundamentá-la, como: a agricultura, engenharia, química, design, tecnologia em geral, sociologia, economia, a gestão e logística, por exemplo. A indústria têxtil por possuir uma cadeia produtiva muito longa, é uma das que tem maior potencial de causar impactos ambientais negativos (Guimarães e Baruque, 2014).

No Brasil o setor têxtil é expressivo economicamente empregando em torno de 1,7 milhões de trabalhadores de forma direta e, cerca de 2 milhões de forma indireta. Ele representa uma força produtiva nacional que ultrapassa 30 mil empresas de variados portes, ocupa no ranking mundial o quarto lugar dentre os produtores de 
vestuário e a quinta colocação em produtor de fibras (ABIT, 2012).

A Agência Brasileira de Desenvolvimento Industrial (ABID) a partir de um estudo prospectivo setorial têxtil e de confecção, aponta dentre as tendências de mercado até 2025, para uma vertente estratégica de meio ambiente, aumentando a produção e uso de insumos que não agridem o meio ambiente, para a fabricação de produtos mais sustentáveis (ABID, 2012).

Dentro da preocupação com contaminantes industriais a técnica AIT (Avaliação e Identificação de Toxicidade), proposta pela Agência Americana de Proteção ao Meio Ambiente e acolhida mundialmente, tem como foco melhorar a qualidade dos efluentes industriais quanto à toxicidade, identificando a substância causadora e possibilitando a troca da substância tóxica por uma que desempenhe a mesma função com impacto menor ou ausente (Jeronimo et al., 2015).

Para Viana (2012) a predominância do uso dos corantes sintéticos dificultou o desenvolvimento e adaptação do tingimento natural nas tecelagens modernas. Há um interesse crescente em investigar os corantes naturais e transformá-los em uso de escala comercial.

O corante natural é uma substância colorida extraída da natureza (ex: solo), de matéria vegetal ou animal por processos fisico-químicos (dissolução, precipitação) ou bioquímicos (como a fermentação), devem ser solúveis no meio líquido onde é mergulhado o material a tingir.

Nos últimos anos, consumidores de produtos coloridos apresentaram uma rejeição ao uso de corantes sintéticos e artificiais. Ao mesmo tempo, a coloração utilizando fontes naturais ganhou importância na indústria, confecção e moda.

Aponta-se que os pigmentos coloridos naturais possuem menor estabilidade a luz, temperatura, oxigênio, alcalinidade, alvejamento e ação abrasiva. Contudo, agentes oxidantes e quelantes podem conferir maior estabilidade a estes compostos naturais (Viana, 2012).

Os pigmentos naturais podem ser distribuídos em cinco classes estruturais orgânicas: os tetrapirróis, tetraterpenos, quinonas, O-heterocíclicos e Nheterocíclicos (Schiozer e Barata, 2007).

Dentre os corantes conhecidos e utilizados, mesmo que artesanalmente no tingimento, esta o hibisco Hibiscus sabdariffa L. Ele possui propriedades antioxidantes e antimicrobianas, sendo empregado para fins medicinais e alimentares. As flores são fonte de antocianinas, visualizadas no espectro colorido de rosa a púrpura (Maciel et al., 2012).

O urucum Bixa orellana L. é original da América do Sul e suas sementes oferecem um corante do grupo carotenoide (tons amarelos a laranja), além de ser utilizado na indústria têxtil, pode ser usado na indústria de alimentos e farmacêutica (Schiozer e Barata, 2007; Vilar et al., 2016).

Uma parceria de cooperação científica firmada entre a Associação Brasileira da Indústria Têxtil (Abit), o Sindicato das Indústrias Têxteis Paulistas (Sinditêxtil-SP) e o Ministério da Ciência, Tecnologia e Inovação (MCTI) assinada em setembro 2015, projeta a indústria têxtil para objetivos de tornar-se mais competitiva e sustentável (Agência CT\&I, 2015).

Portanto, esse artigo tem como objetivo avaliar, através de bioensaios com plantas superiores, a toxicidade de corantes naturais do grupo carotenoide (urucum) e antocianinas (hibisco), extraídos de fontes vegetais e empregados no tingimento têxtil.

\section{Metodologia}

Para a avaliação da toxicidade das plantas analisadas, foram usadas os seguintes procedimentos:

1. Corantes naturais: foram selecionados dois corantes, sendo um deles o urucum do grupo carotenóide e o outro o hibisco do grupo antocianina, extraídos respectivamente das sementes de Bixa orellana L. e das flores de Hibiscus sabdariffa L.

2. Meio de extração: foram realizadas extrações dos corantes naturais em água (hibisco) e também na solução aquosa de hidróxido de sódio 1,0 M (urucum). 
3. Processo de extração: Para extração do corante, a partir da matéria-prima vegetal, utilizou-se $1 \mathrm{~g}$ da parte vegetal, colocada em becker com $40 \mathrm{~mL}$ do meio de extração, em agitador magnético (AM) por $1 \mathrm{~h}$ e temperatura de $40{ }^{\circ} \mathrm{C}$.

4. Germinação e crescimento: foram avaliadas amostras dos dois corantes para as análises germinativas e de crescimento vegetal em solo, segundo a norma ABNT NBR ISO 11269-2:2014 (ABNT, 2014). O vegetal-teste selecionado foi Zea mays L. O experimento foi realizado com três réplicas, sendo que os vasos de polietileno contendo 400 g de solo padrão, foram mantidos em local com fotoperíodo de $12 \mathrm{~h}$ (claro/escuro) à temperatura de $30{ }^{\circ} \mathrm{C} \pm$ $2{ }^{\circ} \mathrm{C}$. O solo recebeu irrigação constante ao longo do experimento com dosagens nas diluições de $100 \%$, 50\% e $25 \%$ dos corantes extraídos. Foram plantadas cinco sementes de milho por vaso. Após a germinação de $50 \%$ das sementes, foram deixadas em cada vaso apenas duas plântulas de milho. Após 21 dias da emergência de $50 \%$ das sementes, foi determinado o comprimento das raízes e da parte aérea. O controle foi irrigado com água destilada.

5. Análise estatística: Foi empregado para análise estatística o Teste de Dunnett (Vieira e Hoffmann, 1989).

\section{Resultados e discussão}

Os resultados de germinação das plântulas de Zea mays estão expressas em porcentagem (\% de germinação).

$\mathrm{O}$ crescimento radicular (CR) e crescimento aéreo (CA) estão expressos em média e centímetros.

A duração total dos testes foi de 28 dias, sendo 21 dias contados a partir da germinação de $50 \%$ das sementes.

Os resultados de germinação e crescimento de $Z$. mays foram comparados em relação aos controles (médias) pelo teste de Dunnett $(\mathrm{p}<0.01$ e $\mathrm{p}<0.05)$, determinando quando os vegetais foram afetados positiva ou negativamente pelas amostras de corantes.

A emergência de pelo menos 50\% das sementes ocorreu no $6^{\circ}$ dia após o plantio para urucum e, no $7^{\circ}$ dia para hibisco.

As Tabelas 1 e 2 descrevem que a percentagem de germinação foi entre 93\% e $100 \%$ das sementes cultivadas em todos os tratamentos e amostras.

Estes dados confirmam a capacidade germinativa das sementes utilizadas e a eficiência do substrato (solo padrão) nos experimentos.

Tabela 1. Teste de toxicidade com Zea mays - porcentagem de germinação e médias de crescimento exposição ao corante natural urucum.

\begin{tabular}{|lccc|}
\hline Amostra & $\begin{array}{c}\text { \% germinação } \\
\text { (12 dias) }\end{array}$ & $\begin{array}{c}\text { CR (cm) } \\
\text { (28 dias) }\end{array}$ & $\begin{array}{c}\text { CA (cm) } \\
\text { (28 dias) }\end{array}$ \\
\hline Controle & 100 & 40,1 & 36,2 \\
A 100 & 93 & $42,4^{*}$ & 37,9 \\
A 50 & 100 & 41,4 & $39,2 * *$ \\
A 25 & 100 & 41,2 & 37,1 \\
\hline
\end{tabular}

** Teste de Dunnett - diferença significativa $(\mathrm{p}<0.01)$; *Teste de Dunnett - diferença significativa $(\mathrm{p}<0.05)$.

Nas amostras de incorporação ao solo do corante urucum (Tabela 1) e do corante hibisco ao solo (Tabela 2), nas amostras A100, A50 e A25 a porcentagem de germinação foi superior a $90 \%$, não mostrando resultados estatisticamente diferentes do controle, pelo Teste de Dunnett.
Na Tabela 1 esta descrito para a amostra A100 que no crescimento da raiz (CR) houve diferença significativa em relação ao controle, sendo o valor superior para A100. Para o crescimento aéreo (CA) houve incremento do crescimento significativo para C50. 
Mata et al. (2011) em trabalho com Z. mays discutem que as respostas das plântulas pressupõe que os efeitos dos compostos afetem primeiramente a germinação e o desenvolvimento das raízes, pois estas tem a função de absorção de água, nutrientes e outros elementos presentes no solo que podem interferir positiva ou negativamente no desenvolvimento do vegetal.

A presença do corante natural urucum não influenciou negativamente a germinação e o crescimento inicial do vegetal-teste, empregado nos experimentos.

Os testes ecotoxicológicos trazem a compreensão de como os ecossistemas metabolizam, transformam, degradam, acumulam, eliminam ou sofrem a ação das diversas substâncias químicas neles introduzidas. Fundamentam-se no princípio da resposta dos organismos vivos depender da concentração, sinergismo e antagonismo molecular, do tempo de exposição, idade e outras condições estruturais e funcionais dos organismos vivos (Azevedo e Chasin, 2003).

A Tabela 2 revela que a presença do corante natural hibisco acompanhou os valores do controle, tanto para a germinação como para o crescimento inicial de Zea mays.

Tabela 2. Teste de toxicidade com Zea mays - porcentagem de germinação e médias de crescimento exposição ao corante natural hibisco.

\begin{tabular}{|lccc|}
\hline Amostra & $\begin{array}{c}\text { \% germinação } \\
\text { (12 dias) }\end{array}$ & $\begin{array}{c}\text { CR (cm) } \\
\text { (28 dias) }\end{array}$ & $\begin{array}{c}\text { CA (cm) } \\
\text { (28 dias) }\end{array}$ \\
\hline Controle & 100 & 40,1 & 36,2 \\
A 100 & 93 & 40,1 & 36,9 \\
A 50 & 100 & 40,4 & 36,2 \\
A 25 & 100 & 40,2 & 36,1 \\
\hline
\end{tabular}

** Teste de Dunnett - diferença significativa $(\mathrm{p}<0.01)$; *Teste de Dunnett - diferença significativa $(\mathrm{p}<0.05)$.

Não foram observados nos bioensaios em presença dos corantes urucum e hibisco, efeitos agroquímicos tóxicos graves e limitantes para o vegetal testado.

Os resultados iniciais apontam positivamente para a utilização destes corantes naturais nas condições experimentais testadas.

Pode-se afirmar que estes resultados são ainda preliminares e inúmeros testes serão realizados com diferentes organismos-alvo contemplando: vegetais dicotiledôneos, outros níveis tróficos (consumidores e decompositores) e no ambiente aquático.

As leis em vigor, os acordos nacionais e internacionais, os protocolos e guias de procedimentos, potencializam para o setor têxtil a busca da eficiência de seus processos, caminhando para um ajuste eficiente e formal no sentido de utilizar processos mais sustentáveis. Os "materiais verdes” são uma promessa de futuro (Rio 2016, 2014).

\section{Conclusões}

$\mathrm{O}$ uso de corantes naturais para tingimentos no mundo da moda pode ser uma alternativa eficaz para o binômio indústria têxtil-sustentabilidade.

A pesquisa científica na área ambiental contribui com a conservação da biodiversidade e com o equilíbrio da natureza. Pode apontar as necessidades e modelos adequados de manutenção, de correção ou remediação dos ambientes submetidos às atividades antrópicas.

A proposta deste projeto de pesquisa terá continuidade e seus resultados poderão nortear os empresários e usuários em geral, através de dados científicos, em suas atividades de tingimento e uso de produtos naturais para colorir substratos têxteis. 
Estes resultados, preliminarmente, aprovam o uso dos corantes urucum e hibisco para aplicação em tingimentos têxteis.

Estando encadeados com protocolos e acordos em vigor no setor produtivo têxtil brasileiro para a geração de conhecimento, os resultados desta pesquisa poderão conduzir à inovação e sustentabilidade esperadas pelo empresário e pelo consumidor do século XXI.

\section{Declaração de conflito de interesses}

A autora declara não haver conflito de interesses.

\section{Referências}

ABDI - Agência Brasileira de Desenvolvimento Industrial. Estudo prospectivo setorial: têxtil e confecção. Brasília: ABDI, 2012.

ABIT - Associação Brasileira da Indústria Têxtil e de Confecção. Têxtil e Confeç̧ão: inovar, Desenvolver e Sustentar. Brasília: CNI/ABIT, 2012. (Cadernos Setoriais Rio+20).

ABNT - Associação Brasileira de Normas Técnicas. ABNT NBR ISO 11269-2:2014 Toxicidade do solo - Determinação dos efeitos de poluentes na flora terrestre. Parte 2: Efeitos do solo contaminado na emergência e no crescimento inicial de vegetais superiores. Rio de Janeiro: ABNT, 2014.

Agência Gestão CT\&I. Disponível em: $<$ http://www.agenciacti.com.br>. Acesso em: 14 nov. 2015.

Azevedo, F. A; Chasin, A. A. M. As bases toxicológicas da toxicologia. São Carlos: Rima, 2003.

Berlin, L. G. A indústria têxtil brasileira e suas adequações na implementação do desenvolvimento sustentável. Moda Palavra e-periódico, n. 13, p. 15-45, 2014. Disponível em: $<$ http://www.revistas.udesc.br/index.php/modap alavra/article/view/5117/3831>. Acesso em: 14 nov. 2015.

Guimarães, K. O.; Baruque-Ramos, J. Potencial de reciclagem têxtil no Brasil em âmbito de gestão ambiental. Anais do $2^{\circ}$ Congresso Científico Têxtil e de Moda, São Paulo, 2014.

Jeronimo, R. A. S.; Morais, M. M.; Paz, Y. M.; Holanda, R. M. Gerenciamento de resíduos sólidos industriais e a produção mais limpa, estudo de caso em indústria de cerâmica vermelha. Proceding of Cleaner Production Towards a Sustainable Transition, São Paulo, 20 a 22 de maio de 2015 .

Maciel, M. J.; Paim, M. P.; Carvalho, H. H. C.; Wiest, J. M. Avaliação do extrato alcoólico de hibisco (Hibiscus sabdariffa L.) como fator de proteção antibacteriana e antioxidante. Rev. Inst. Adolfo Lutz, v. 71, n. 3, p. 462-470, 2012. Disponível em: <http://revistafitos.far.fiocruz. br/index.php/revista-fitos/article/view/71/70>. Acesso em: 14 nov. 2015.

Mata, J. F.; Pereira, J. C. S.; Chagas, J. F. R.; Vieira, L. M. Germinação e emergência de milho híbrido sob doses de esterco bovino. Amazônia: Ciência e Desenvolvimento, v. 6, n. 12, p. 31-40, 2011.

Rio 2016. Guia de sustentabilidade para produtos têxteis. Rio de Janeiro: Rio 2016, $2014 . \quad$ Disponível em: <http://portaldesuprimentos.rio2016.com/wpcontent/uploads/2014/05/Rio-2016-Guia-deSustentabilidade-para-Produtos-Téxteis-2.pdf $>$. Acesso em: 14 nov. 2015.

Schiozer, A. L.; Barata, L. E. S. Estabilidade de corantes e pigmentos de origem vegetal. Revista Fitos, v. 3, n. 2, p. 6-24, 2007. $<$ http://revistafitos.far.fiocruz.br/index.php/revis ta-fitos/article/view/71/70>. Acesso em: 14 nov. 2015.

Tartaglione, C.; Gallante, F.; Guazzo, G. Sostenibilità: MODA Cosa significa, come si applica, dove sta andando l'idea di sostenibilità nel sistema moda. Ares 2.0, SOGES, 2012. $<$ http://www.aresduezero.it/phocadownload/rice rca_innovazione_sostenibilita/Sotenibilita_mod a_2012.pdf>. Acesso em: 14 nov. 2015.

Viana, T. C. Corantes naturais na indústria têxtil: como combinar as experiências do passado com as demandas do futuro? Belo Horizonte: Universidade Estadual de Minas Gerais, 2012. (Dissertação de mestrado).

Vieira, S.; Hoffmann, R. Estatística experimental. São Paulo: Atlas, 1989. 
Vilar, D. A.; Vilar, M. S. A.; Lima e Moura, T. F. A.; Raffin, F. N.; Oliveira, M. R.; Franco, C. F. O.; Athayde-Filho, P. F.; Diniz, M. F. F. M.; Barbosa-Filho, J. M. Traditional uses, chemical constituents, and biological activities of Bixa orellana L.: a review. The Scientific World Journal, v. 2014, Article ID 857292, 1 p., 2014. http://dx.doi.org/10.1155/2014/857292 permite uso irrestrito, distribuição e reprodução em qualquer meio, desde que a obra original seja devidamente citada.

Rev. Bras. Gest. Amb. Sustent., 2017, v. 4, n. 7, p. 151-157. 